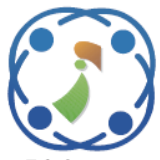

\title{
Touch and Step Voltage Evaluation based on Computer Simulation for a Mass Rapid Transit System in Thailand
}

\author{
Chaiyut Sumpavakup $^{1 *} \quad$ Kritsada Mongkoldee $^{2} \quad$ Tosaphol Ratniyomchai $^{2}$ \\ Thanatchai Kulworawanichpong ${ }^{2}$
}

${ }^{1}$ Research Centre for Combustion Technology and Alternative Energy and College of Industrial Technology, King Mongkut's University of Technology North Bangkok, Bangkok 10800, Thailand

${ }^{2}$ School of Electrical Engineering, Suranaree University of Technology, Nakhon Ratchasima 30000, Thailand

* Corresponding author's Email: chaiyut.s@ cit.kmutnb.ac.th

\begin{abstract}
This article proposed a computer-based simulation approach to estimate touch and step voltages due to a lightning strike at a mass rapid transit railway station. A purely resistive circuit model of a station lightning protection, and earthing \& bonding system is formed in MATLAB/Simulink with Yaek Nonthaburi 1 passenger station of MRT purple line in Bangkok, Thailand as a case study. The simulation investigated the consequence of a lightning strike at four different locations on the roof of the station and examined whether or not the lightning protection system met the standard requirements. The results showed the touch voltages, step voltages and body currents in a steady state together with the impact on the human body standing in the station. The simulation can guarantee the effectiveness of the proposed model, and also proved that the lightning protection system of the station is able to conform to the standard and there is no harm for the passenger in the station.
\end{abstract}

Keywords: Touch voltage, Step voltage, Lightning protection system, Mass rapid transit system, Computer simulation.

\section{Introduction}

An impact of lightning strikes can create hazards to persons and installations not only directly by high voltages and thermal effects, but also indirectly by causing panic and damage to railway safety related systems. Buildings, bridge, outdoor installations and other structures exposed to direct lightning strikes require an external lightning protection system such as surge arresters [1]. In addition, in [2] proposed an enhanced efficiency of existing lightning protection based on lightning and surge standard mainly on the EN series 62305. Internal lightning protection of electrical equipment is also required against the danger of damage by over-voltages and partial lightning currents caused by lightning strikes. For the DC railways, there are risks of metallic corrosion due to stray current and electrical hazards leading to a danger of passengers and structural damages to the railway station. The earthing and bonding strategy developed and implemented for the elevated DC railway, for example, in Caulfield to Dandenong level Crossing Removal Project [3]. Therefore, the evaluation of an existing lightning protection is very important. In [4], a new inspection equipment and a new circuit structure has been developed to evaluate and measure both the low-frequency parameter (earth resistance) and high-frequency parameters (earth impedance and voltage difference) of the lighting protection performance of earthing system in railway substation. In addition, in [5] proposed a lightning disturbance recognition method to recognize the high-frequency components which cause the relay protection malfunction in the traction substation by using wavelet energy moment and verified by the simulation signals.

The relevant standards shall be applied for the protection of life and property against lightning. For instance, most of the mass rapid transit systems are elevated railways such as BTS skytrain and MRT purple line in Bangkok, Thailand; as a consequence, the structures of these railways are particularly 
vulnerable to lightning strikes during the storm season. Another example of the standardization and guidance of the lightning protection system was required to efficiently reduce the train operation disruptions due to the shutdown of power supply effected by the lightning strikes in Bogor Station of DAOP 1 Jakarta, Indonesia [6]. The awareness of the design of the lightning protection is important which eventually should ensure that fault or lightning currents would not impact the equipment and passenger in the railway station [7].

From those reasons of several damages, the estimation of touch and step voltages, which is another method to assess the lightning protection, due to lightning impulses and the impacts on the human body in a railway station is paramount. Accordingly, the simulation model is needed for the preliminary estimation in order to examine the lightning protection system's compliance with the standard prior to actual operation.

Several methods involving lightning event simulation such as touch and step voltages, safety evaluation etc. have been widely studied and discovered. In [8], an equivalent circuit of a human body was proposed to calculate the touch voltage in the scenario of a lightning strike on a telephone line. The body currents were obtained in two simulation cases: a human holding a telephone and a human standing close to a telephone. The model employed the finite-difference time-domain method (FDTD). There is a variety of research in which an electromagnetic simulation method has been performed to study the electric field intensity caused by lightning and also the touch and step voltages. Unlike the electrostatic counterpart [9], the inductive effects of lightning on the touch and step voltages can be realised [10-12]. The touch and step voltages have been studied in many aspects. Suchanek, Hinrichsen, Brocke and Muller [13] compared four step voltage limits from different sources, then IEC 60479 [14] was chosen for safety consideration. The research also used 3D FEM simulation to investigate different earth termination systems for a rectangular building. Nayel, Zhao, He, Cai and Wang [15] studied a more accurate method, i.e. by including the modelling of a tower foot as an impedance rather than a pure resistance, to calculate the touch and step voltages around a transmission tower foot. The impact of the step voltage on parts and postures of a human body was rigorously researched in [16] using voxel-based body models. Apart from the aforementioned literature, much of the research has only studied the touch and step voltages on a substation ground grid $[17,18]$ and a simple structure building. To expand the application of this field of research, this paper presents a method of touch and step voltages estimation using a simplified pure resistive circuit model, i.e. for ease of creating and running the large detailed model in a computer software, and uses the model to estimate the touch and step voltages, and safety consideration at one of the passenger stations of MRT purple line in Bangkok. In other words, another aim of the paper is to check if the lightning protection system of the station satisfies a standard and if the person touching a conductive part in the station is out of danger from lightning.

This paper is organised into 7 sections. A touch and step voltage calculation method and the impact of those voltages to human body according to the standard are presented in section 2 and 3, respectively. The proposed simulation modelling is described in section 4. Section 5 explains the details and structure of the study case using one of the MRT purple line passenger stations in Bangkok. The simulation results are summarised in section 6 . The paper is finally concluded in section 7 .

\section{Calculation of touch and step voltage}

A step voltage is the voltage between the feet of a person standing near an energized grounded object (lightning flash to the structure). It is equal to the difference in voltage, given by the voltage distribution curve as shown in Fig. 1, between two points at different distances from the electrode. A person could be at risk of injury during a lightning strike simply by standing near the grounding point. A touch voltage is occurred in the same process as a step voltage, but the voltage difference being considered exists between the hand and feet.

The calculation of the touch voltage can be performed by using an equivalent circuit in Fig. 2, which is either the Thevenin or Norton equivalent circuit. The circuit includes the total body impedance $(\mathrm{Zb})$, the additional resistance for shoes (Ra1) and standing surface (Ra2), and the source voltage (Us) or the prospective touch voltage (Utp). Surface 1 and 2 denote the standing surface and earth, respectively. The effective touch voltage (Ute) is determined by measuring the voltage across the series resistance, $\mathrm{Zb}$ and Ra1. Likewise, the calculation of the step voltage can be done in the same manner as that of the touch voltage, which is further described in section 4 .

The total human body impedance for a hand-tohand current path at $50 \%$ probability is indicated in [14]. By applying the reduction factor $r=0.75$ [14], the total human body impedance for a hand-to-feet current path is obtained in Table 1. In this study, the additional resistances $\mathrm{Ra} 2$ and $\mathrm{Ra} 1$ are assumed to be 


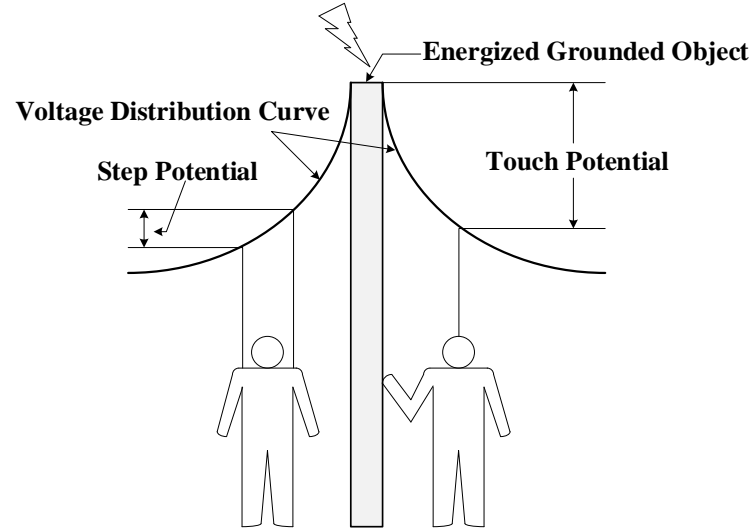

Figure. 1 Voltage distribution curve [19]

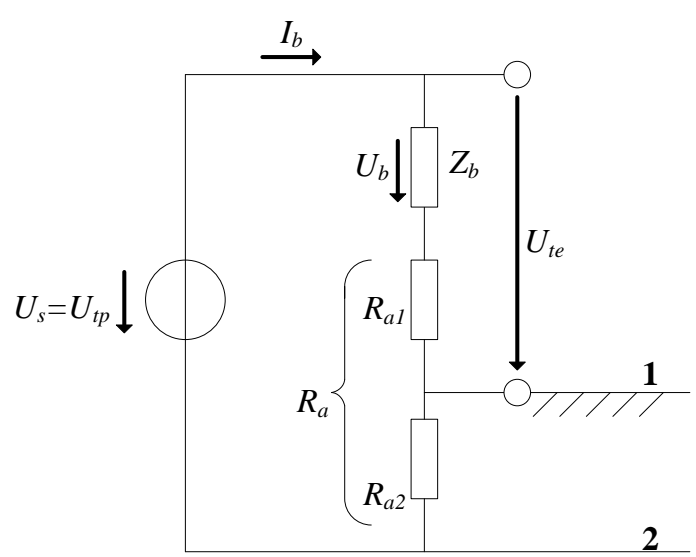

Figure. 2 Equivalent circuit for the calculation of the effective touch voltage [20]

$150 \Omega$ and $1000 \Omega$ (for old wet shoes with a shortterm condition), respectively. Generally, Ra2 can be calculated by Ra $2=\rho s \times 1.5 \mathrm{~m}-1$, where $\rho$ s is soil resistivity at the standing surface in $\Omega \mathrm{m}$. According to the EN50122-1 standard, body currents, body voltages and touch voltages as a function of the time duration in DC traction systems are tabulated in Table 2.

\section{Impact of touch and step voltages on human body}

The risk of electrocution due to the touch voltage is greater than that of the step voltage because the passage of the flow of a current is closer to the heart region. Fig. 1 depicts the step and touch voltage gradients near the structure.

For a given current path through the human body, the danger to a person depends mainly on the magnitude and duration of the current flowing in the body. The necessary criterion is the admissible limit of the touch voltage as a function of time. The effects of alternating current $(50 / 60 \mathrm{~Hz})$ and direct current electric shock on human beings are described in IEC
60479- 1 (IEC TS 60479-1:2005) covering the whole range of shock durations from $0.1 \mathrm{~ms}-10 \mathrm{~s}$. A unidirectional single impulse current of short duration, up to $10 \mathrm{~ms}$, may be a source of danger. The effects of the impulse currents on human beings and livestock are illustrated in IEC 60479-2 (IEC TS 60479-2: 2007).

The specific fibrillating energy $F_{e}$ for a single impulse of the peak current of $I_{p}$ with the shock duration of $t_{i}$ can be determined by the following equation.

$$
F_{e}=I_{r m s}^{2} \times t_{i}
$$

where $I_{r m s}$ is the root-mean-square (rms) value of the impulse current $\left(I_{r m s}=I_{p} / \sqrt{6}\right)$.

The threshold of ventricular fibrillation depends on the duration and magnitude of the impulse current. The thresholds for the ventricular fibrillation are shown in Fig. 3 for unidirectional impulses with shock duration of less than $10 \mathrm{~ms}$.

The heart-current factor permits the calculation of the current Ih, as shown in Eq. (2), flowing through the paths other than the left-hand-to-feet path which represents the same level of danger of ventricular fibrillation as that corresponding to Iref for the lefthand-to-feet path.

$$
I_{h}=\frac{I_{r e f}}{F},
$$

where Iref is the body current for the left-hand-to-feet path. Ih is the body current for the paths given in Table 3. $\mathrm{F}$ is the heart-current factor given in Table 3.

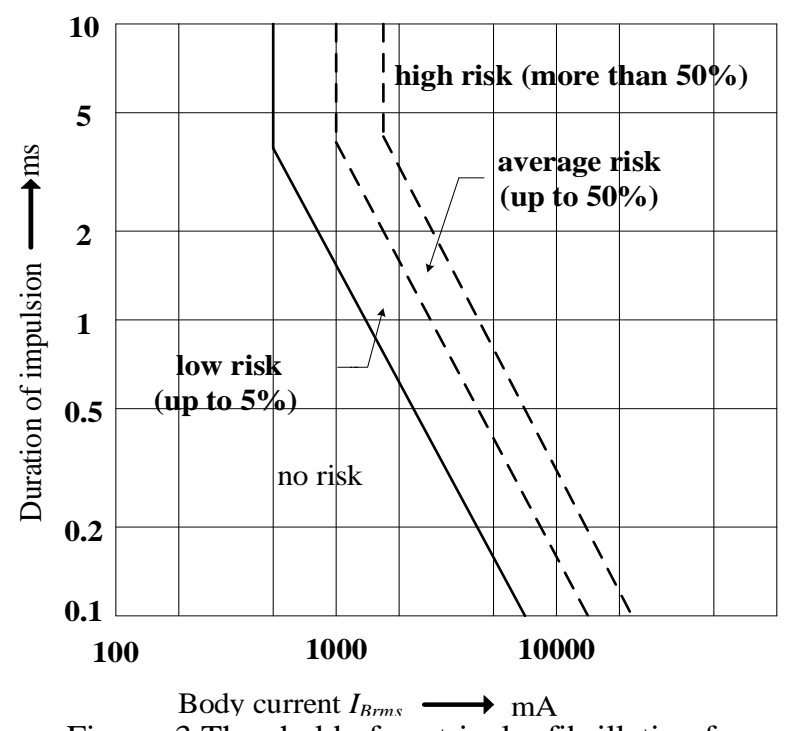

Figure. 3 Threshold of ventricular fibrillation for unidirectional impulses [21] 
Table 1 . Body impedance $Z_{b}$ and body current $I_{b}$ (Table D.1 in [20])

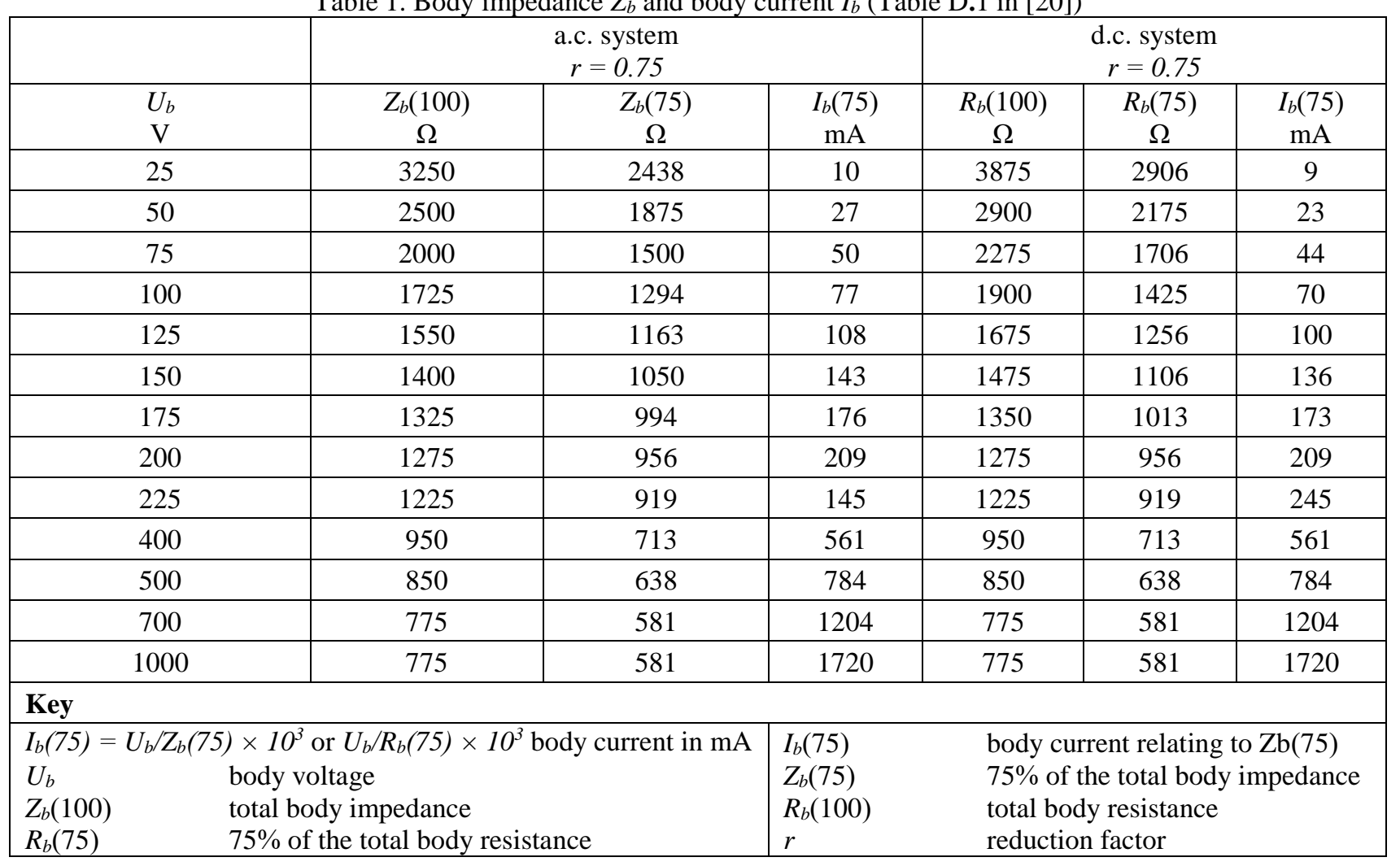

Table 2. Body currents, body voltages and touch voltages as function of time duration in D.C. traction systems (Table

\begin{tabular}{|c|c|c|c|c|c|}
\hline \multicolumn{6}{|c|}{ D.3 in [20]) } \\
\hline $\begin{array}{c}t \\
(\mathrm{~s})\end{array}$ & $\begin{array}{c}I_{c l} \\
(\mathrm{~mA})\end{array}$ & $\begin{array}{l}U_{c l} \\
(\mathrm{~V})\end{array}$ & $\begin{array}{c}U_{b, \max } \\
(\mathrm{V})\end{array}$ & $\begin{array}{c}U_{t e, \max } \\
\text { long-term }(\mathrm{V})\end{array}$ & $\begin{array}{c}U_{t e, \max } \\
\text { short-term }(\mathrm{V})\end{array}$ \\
\hline$>300$ & 140 & 153 & 120 & 120 & - \\
\hline 300 & 140 & 153 & 150 & 150 & - \\
\hline 1 & 150 & 160 & 160 & 160 & - \\
\hline 0.9 & 160 & 167 & 165 & 165 & - \\
\hline 0.8 & 165 & 170 & 170 & 170 & - \\
\hline 0.7 & 175 & 177 & 175 & 175 & - \\
\hline$<0.7$ & 175 & 177 & 175 & - & 350 \\
\hline 0.6 & 180 & 180 & 180 & - & 360 \\
\hline 0.5 & 195 & 191 & 190 & - & 385 \\
\hline 0.4 & 215 & 204 & 205 & - & 420 \\
\hline 0.3 & 240 & 222 & 220 & - & 460 \\
\hline 0.2 & 275 & 246 & 245 & - & 520 \\
\hline 0.1 & 340 & 287 & 285 & - & 625 \\
\hline 0.05 & 410 & 327 & 325 & - & 735 \\
\hline 0.02 & 500 & 372 & 370 & - & 870 \\
\hline \multicolumn{6}{|l|}{ Key } \\
\hline \multicolumn{3}{|c|}{$\begin{aligned} U_{t e, \max }= & U_{c l}+R_{a l} \times I_{c l} \times 10^{-3}(\text { short-term }) \\
& \text { body current which corresponds to curve c1 } \\
I_{c l} & \text { in IEC/TS } 60479-1: 2005 \\
U_{t e, \max } & \text { maximum permissible effective touch voltage }\end{aligned}$} & \multicolumn{3}{|c|}{$\begin{array}{ll}t & \text { time duration of current flow } \\
U_{c l} & \text { body voltage, corresponds to } I_{c l} \\
U_{b, \max } & \text { maximum body voltage }\end{array}$} \\
\hline
\end{tabular}


Table 3. Heart-current factor $F$ for different current paths

\begin{tabular}{|l|c|}
\hline \multicolumn{1}{|c|}{ Current path } & $\begin{array}{c}\text { Heart-current } \\
\text { factor } F\end{array}$ \\
\hline $\begin{array}{l}\text { Left hand to left foot, right foot or } \\
\text { both feet }\end{array}$ & 1.0 \\
\hline Both hands to both feet & 1.0 \\
\hline Left hand to right hand & 0.4 \\
\hline $\begin{array}{l}\text { Right hand to left foot, right foot } \\
\text { or to both feet }\end{array}$ & 0.8 \\
\hline Back to right hand & 0.3 \\
\hline Back to left hand & 0.7 \\
\hline Chest to right hand & 1.3 \\
\hline Chest to left hand & 1.5 \\
\hline $\begin{array}{l}\text { Seat to left hand, right hand or to } \\
\text { both hands }\end{array}$ & 0.7 \\
\hline Left foot to right foot & 0.04 \\
\hline
\end{tabular}

\section{Simulation modeling}

To simulate the touch and step voltages caused by a lightning strike, a software that allows using various forms of electrical sources, e.g., AC, DC or impulse is necessary. The earthing and bonding model, which is a combination of the air termination system, the down conductor system and the earth termination system, is constructed by using a concept of resistive circuits. This model is energized by various sources to enable the study of the touch and step voltages simulation. To exhibit the use of computer modeling and simulation in this scope of work, MATLAB/Simulink is a tool to perform this simulation.

The model is comprised of the source of lightning, the resistive network of the structure and a human represented by a resistor $\left(R_{b}\right)$, see Fig. 4 , i.e. the figure shows a simplified resistive network of the model. The resistive circuit of the building structure is obtained by creating an equivalent circuit from the structure drawings, particularly a given earthing and bonding drawing. The lightning current is represented by a current source in which the current is the peak value of the lightning impulse. The Thevenin or Norton equivalent source can be established from the resistive circuit and the lightning current source; this equivalent source replaces the voltage source $\left(U_{s}\right)$ in Fig. 2, then the final equivalent circuit to determine the touch voltage is given as shown in Fig. 5 (a). The Thevenin equivalent voltage $\left(V_{T H}\right)$ and resistance $\left(R_{T H}\right)$ are determined by using the measuring blocks in MATLAB/ Simulink. In addition to the touch voltage calculation, the equivalent circuit for determining the step voltage is slightly adapted from that of the touch voltage. The additional structural component is the resistive model

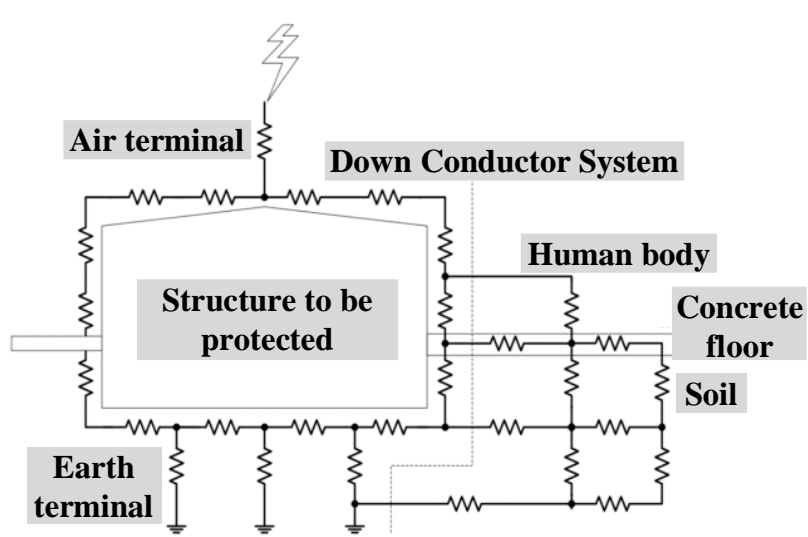

Figure. 4 Resistive network of the step and touch voltage calculation model

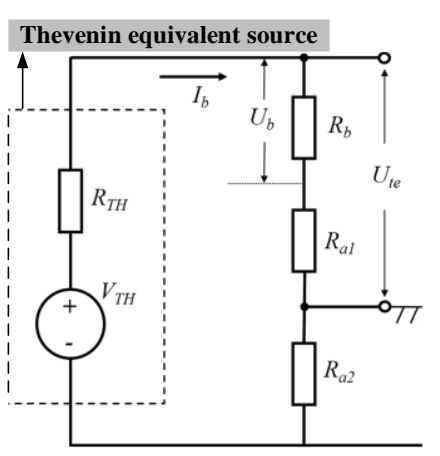

(a)

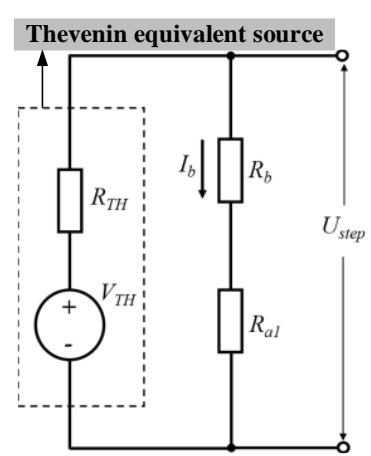

(b)
Figure. 5 Equivalent circuit of the touch voltage calculation: (a) touch voltage and (b) step voltage

of the floor material; this equivalent resistance of the floor is incorporated into the Thevenin equivalent resistance. The body current path is left-foot-to-rightfoot or right-foot-to-left-foot, as a consequence, the resistance of the path includes the body resistance and shoes resistance as shown in Fig. 5 (b), where $U_{\text {step }}$ denotes the voltage across two feet.

\section{Case study}

A Yaek Nonthaburi 1 passenger station (S09) of MRT purple line in Bangkok, Thailand is a case study for validation of the simulation model as shown in Fig. 6. The resistive model of the station contains the pier (type C1) and the steel structure of the station roof; the model is formed according to the structure drawings together with the earthing and bonding drawings. The diagram showing the composition of the model and the resistive network model of the station are exhibited in Figs. 7-10. The complete simulation block model built in MATLAB/Simulink is exhibited in Fig. 11. 


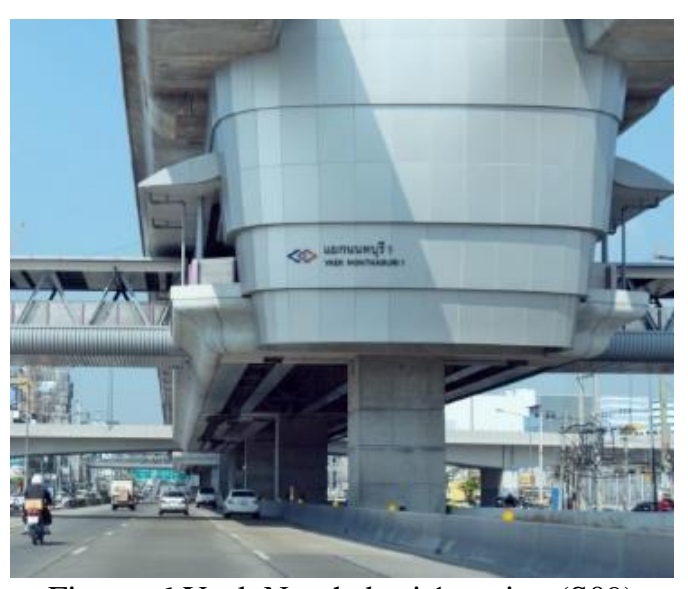

Figure. 6 Yaek Nonthaburi 1 station (S09)
The simulation is broken down into four cases, each of which has different lightning strike locations at the roof top (air terminals). Fig. 8 also indicates the locations of the lightning strike. Two types of the lightning impulses, i.e. positive and negative impulse, are employed in each simulation case; the impulse curves are shown in Fig. 8 with the dotted line representing the negative impulse and the solid line representing the positive impulse. Even though the lightning current is in the impulse form, in this simulation only adopts the peak values as a constant current source: $100 \mathrm{kA}$ for the negative impulse and $200 \mathrm{kA}$ for the positive impulse.

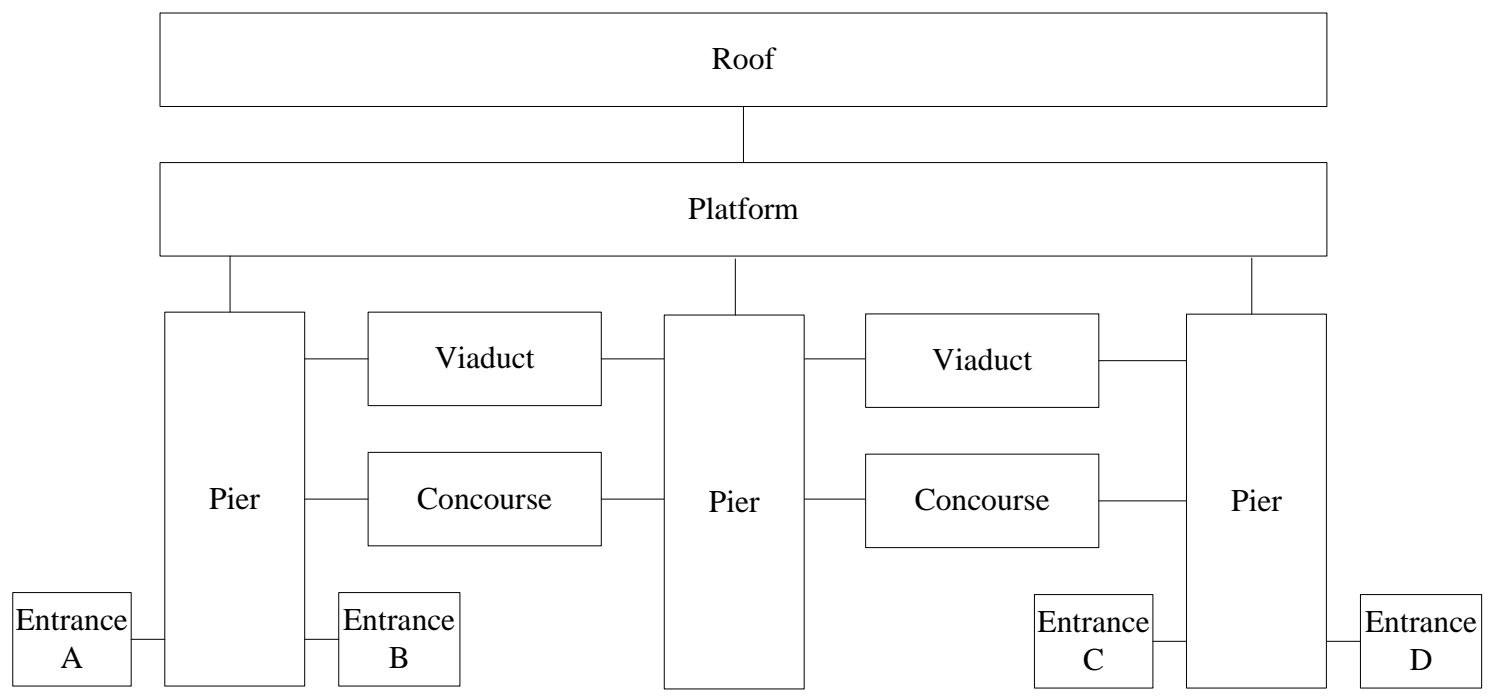

Figure. 7 Internal connection diagram of the simulation model

Table 4. Input data and system parameter setting

\begin{tabular}{|c|c|}
\hline Parameters & Values \\
\hline Human resistance for touch voltage calculation & $1000 \Omega$ \\
\hline Resistivity/resistance of DB25 $\left(\mathrm{A}=490.9 \mathrm{~mm}^{2}\right)$ & $0.2385 \mu \Omega . m(0.486 m \Omega / m)$ \\
\hline Resistivity/resistance of bare copper $\left(\mathrm{A}=70 \mathrm{~mm}^{2}\right.$ and $\left.120 \mathrm{~mm}^{2}\right)$ & $\begin{array}{l}0.0168 \mu \Omega . m \\
0.341 m \Omega / m \text { for } 70 \mathrm{~mm}^{2} \\
0.14 m \Omega / m \text { for } 120 \mathrm{~mm}^{2}\end{array}$ \\
\hline Resistivity of galvanized steel pipe $(\varnothing 25 \mathrm{~mm}, 4 \mathrm{~mm}$ thickness $)\left(\mathrm{A}=263.9 \mathrm{~mm}^{2}\right)$ & $0.1 \mu \Omega . m$ \\
\hline Resistivity of concrete resistance $(320 \mathrm{ksc})$. & $100 \mu \Omega . m$ \\
\hline Resistivity/resistance of ground rod $(\varnothing 16 \mathrm{~mm}$ x $3000 \mathrm{~mm})\left(\mathrm{A}=201.1 \mathrm{~mm}^{2}\right)$ & $0.0168 \mu \Omega . m(83.5 m \Omega / m$ \\
\hline Resistivity of roof (metal sheet), 4mm thickness & $0.1 \mu \Omega . m$ \\
\hline Resistivity of steel plate $(40 \times 5 \mathrm{~mm})$ & $0.1 \mu \Omega . m$ \\
\hline Resistivity of roof column $(\varnothing 406.4 \mathrm{~mm}, 9 \mathrm{~mm}$ thickness $)\left(\mathrm{A}=11,236 \mathrm{~mm}^{2}\right)$ & $0.1 \mu \Omega . m$ \\
\hline Resistivity/resistance of lightning air terminal $(\varnothing 16 \times 1000 \mathrm{~mm})\left(\mathrm{A}=201.1 \mathrm{~mm}^{2}\right)$ & $0.0168 \mu \Omega . m(83.5 m \Omega / m)$ \\
\hline Resistivity/resistance of copper tape $\left(25 \times 3 \mathrm{~mm}, \mathrm{~A}=75 \mathrm{~mm}^{2}\right)$ & $0.0168 \mu \Omega . m(0.224 m \Omega / m)$ \\
\hline Earthing resistance & $0.2 \Omega$ \\
\hline Peak of lightning surge current (class I: IEC62305-1) & $\begin{array}{l}\text { positive impulse }=200 \mathrm{kA} \\
\text { negative impulse }=100 \mathrm{kA}\end{array}$ \\
\hline
\end{tabular}




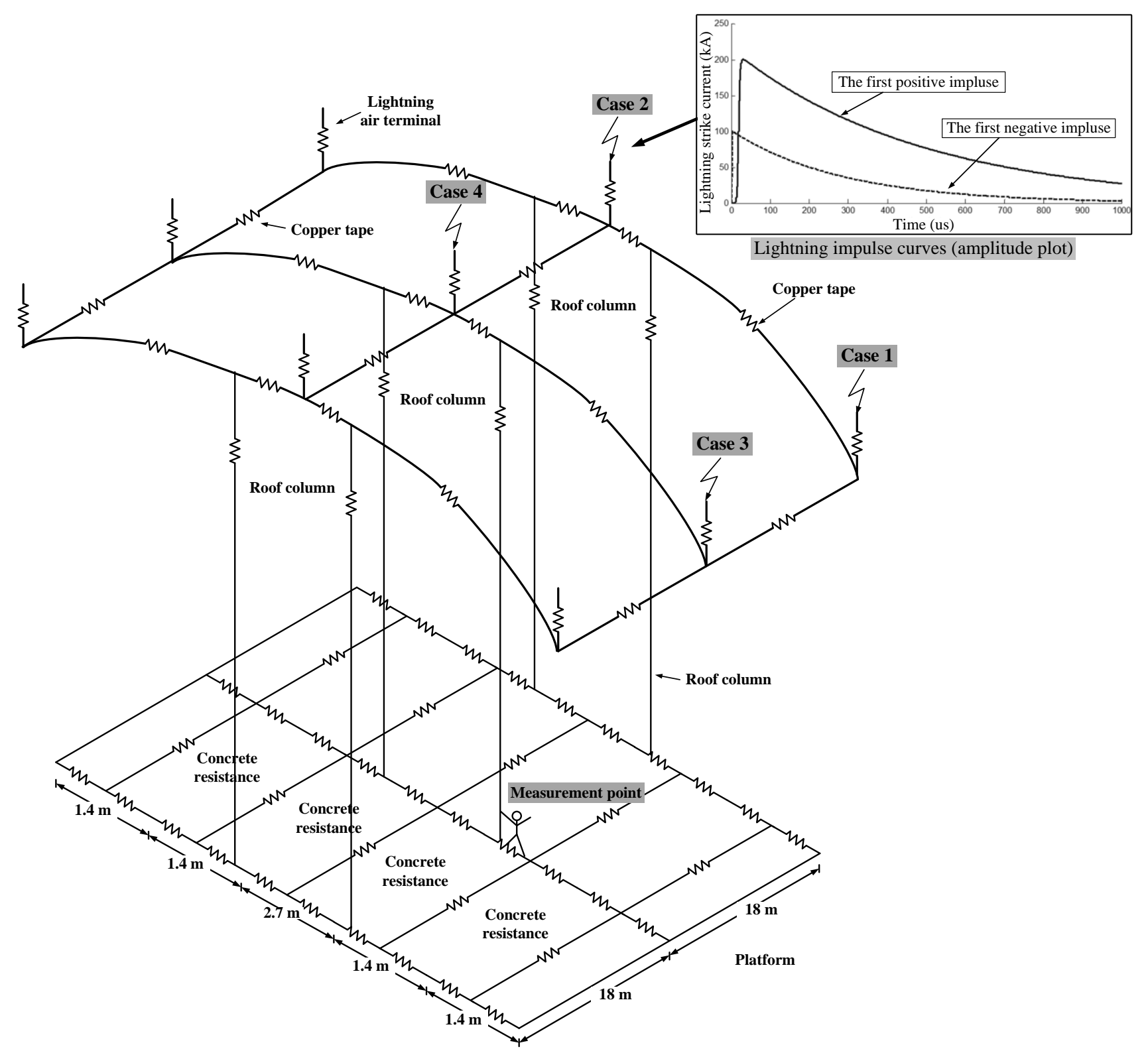

Figure. 8 Roof model, platform model and lightning strike locations for simulation

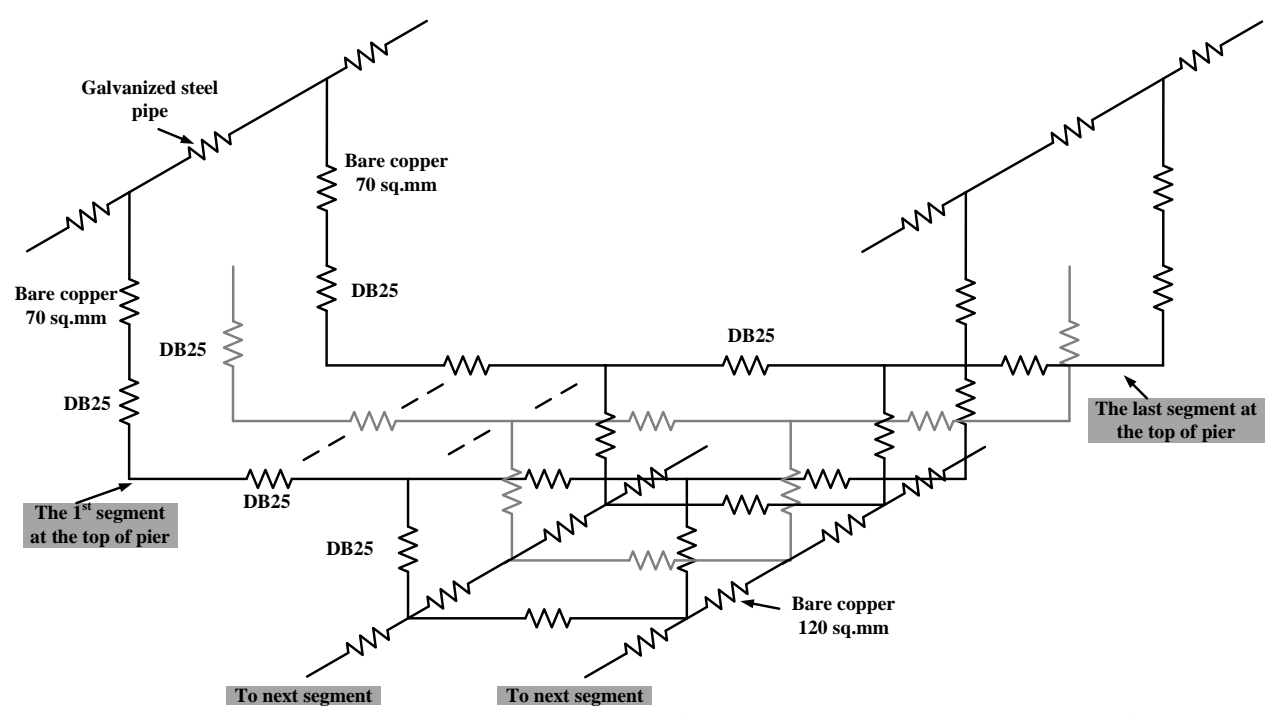

Figure. 9 Viaduct model for simulation (some connections are not shown) 


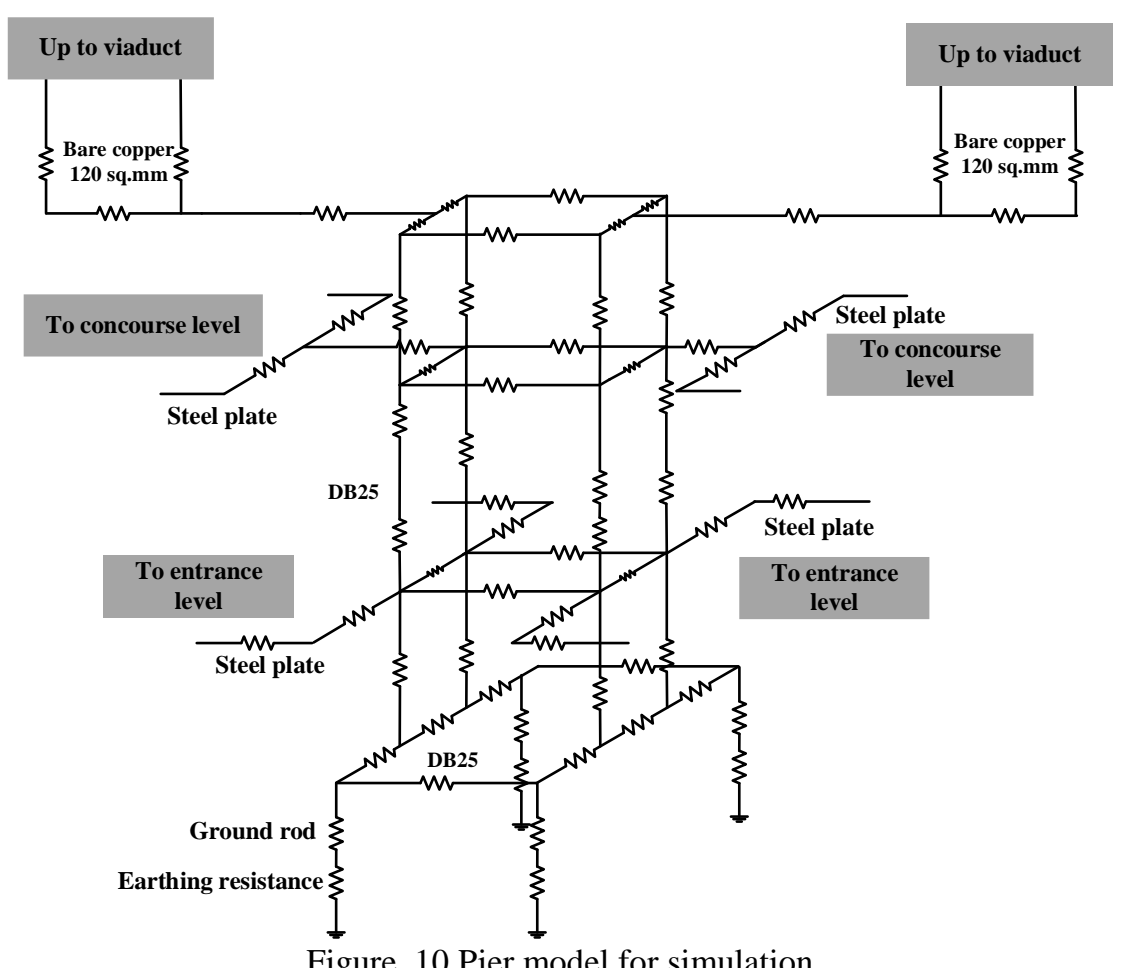

Figure. 10 Pier model for simulation

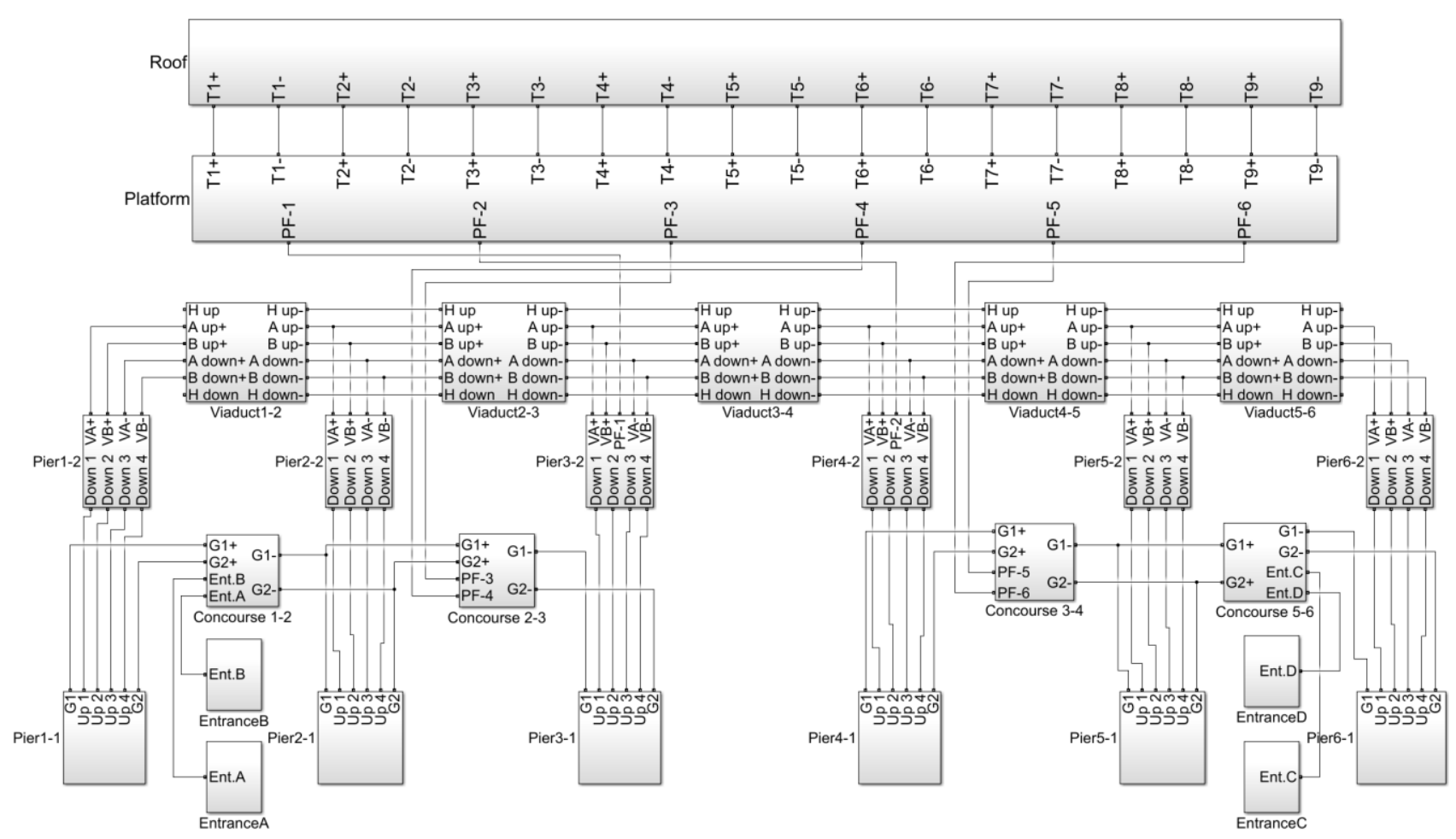

Figure. 11 Connection diagram of the block model in MATLAB/Simulink

In view of using the constant current source, the outcome of the maximum current is obtained in a steady state; the steady state results will suffice to estimate the touch and step voltages and the safety for humans, hence no transient effects are investigated. The parameters used in the simulation are given in Table 4 [14, 22-24].

\section{Simulation results}

The simulation results of the touch and step voltages for the case study are summarised in Table 5 and Table 6 . The results are composed of the rms values of the touch and step voltages, body currents 
Table 5. Simulation results of the touch voltages

\begin{tabular}{|c|c|c|c|c|}
\hline $\begin{array}{c}\text { Lightning } \\
\text { impulse }\end{array}$ & Case & $\begin{array}{c}V_{\text {touch }} \\
(\mathrm{V})\end{array}$ & $\begin{array}{c}\text { Body current } \\
I_{\text {Brms }}(\mathrm{mA})\end{array}$ & Results \\
\hline \multirow{4}{*}{$\begin{array}{c}\text { Positive } \\
\text { impulse }\end{array}$} & 1 & 12.06 & 0.846 & no fibrillation \\
\cline { 2 - 5 } & 3 & 12.22 & 0.857 & no fibrillation \\
\cline { 2 - 5 } & 4 & 30.23 & 2.897 & no fibrillation \\
\hline \multirow{4}{*}{$\begin{array}{c}\text { Negative } \\
\text { impulse }\end{array}$} & 2 & 6.11 & 2.924 & no fibrillation \\
\cline { 2 - 5 } & 3 & 15.12 & 1.060 & no fibrillation \\
\cline { 2 - 5 } & 4 & 15.26 & 1.070 & no fibrillation \\
\hline
\end{tabular}

Table 6. Simulation results of the step voltages

\begin{tabular}{|c|c|c|c|c|}
\hline $\begin{array}{l}\text { Lightning } \\
\text { impulse }\end{array}$ & Case & $\begin{array}{l}V_{\text {step }} \\
(\mathrm{V})\end{array}$ & $\begin{array}{c}\text { Body current } \\
I_{\text {Brms }}(\mathrm{mA})\end{array}$ & Results \\
\hline \multirow{4}{*}{$\begin{array}{l}\text { Positive } \\
\text { impulse }\end{array}$} & 1 & 28.87 & 0.111 & no fibrillation \\
\hline & 2 & 29.26 & 0.112 & no fibrillation \\
\hline & 3 & 79.22 & 0.483 & no fibrillation \\
\hline & 4 & 79.94 & 0.487 & no fibrillation \\
\hline \multirow{4}{*}{$\begin{array}{l}\text { Negative } \\
\text { impulse }\end{array}$} & 1 & 14.43 & 0.040 & no fibrillation \\
\hline & 2 & 14.63 & 0.041 & no fibrillation \\
\hline & 3 & 39.61 & 0.152 & no fibrillation \\
\hline & 4 & 39.97 & 0.153 & no fibrillation \\
\hline
\end{tabular}

and the impact on the human body. Considering Fig. 3 and $\mathrm{c}_{1}$ curve, the body currents in every case are all in the no-risk zone. As a result, no ventricular fibrillation is observed - in other words the personals or passengers in the $\mathrm{S} 09$ station are surely safe during the lightning strike at the roof top. Regarding the touch voltage, and body current as function of time duration in d.c. traction systems shown in Table 2, the results show that the maximum touch voltage and body current of the lightning strike of both positive and negative of $30.52 \mathrm{~V}$ and $2.924 \mathrm{~mA}$ are lower than the minimum touch voltage and body current of 120 $\mathrm{V}$ and $140 \mathrm{~mA}$, respectively. This means that the duration of time of the touch voltage and body current are able to flow through the body with no danger of ventricular fibrillation is more than $300 \mathrm{~s}$. Moreover, the peak current of the positive impulse is twice as many as that of the negative one, then touch and step voltages of the positive impulse cases are approximately double those of the negative impulse cases. It is also noteworthy that the touch and step voltages of Case 3 and 4 for both the positive and negative impulse are considerably greater than the other cases; this outcome is attributed to the closer vicinity of the lightning strike locations. The positive and negative impulse does not provide any significant difference to each other but the magnitudes of the touch voltages, step voltages and body currents.

The simulation results are a preliminary estimation of the touch and step voltage and their impacts on the humans in the S09 station and also validate the proposed model; they guarantee the human protection against lightning and indicate that the lightning protection system of the S09 station is well-designed and compliant with the standard.

\section{Conclusion}

This paper presents a model for the evaluation of the touch and step voltages due to a lightning strike using MATLAB /Simulink. The model is created as a resistive network of the building structure according to the given earthing and bonding drawings. Yaek Nonthaburi 1 passenger station (S09) of MRT purple line in Bangkok is taken as a simulation case study. The simulation has 4 different cases with different lightning strike locations. The results show the touch voltages, step voltages and body currents of each case including the impact on the human body. Among all cases, the maximum touch voltage is $30.52 \mathrm{~V}$ with the body current of $2.924 \mathrm{~mA}$ and the maximum step voltage is $79.94 \mathrm{~V}$ with the body current of $0.487 \mathrm{~mA}$. Both voltage and current are lower than the minimum voltage and body current of $120 \mathrm{~V}$ and $140 \mathrm{~mA}$, respectively, which poses no harm to the human body. The simulation validates the proposed model and also proves that the lightning protection system of the station conforms with the standard; the touch voltages, step voltages and body currents do not exceed the safety criteria. It is concluded that no additional air terminals are required.

\section{Conflicts of Interest}

The authors declare no conflict of interest.

\section{Author Contributions}

conceptualization, Chaiyut; methodology, Chaiyut; software, Chaiyut and Kritsada; validation, Tosaphol and Thanatchai; formal analysis, Chaiyut; investigation, Tosaphol; resources, Chaiyut and Kritsada; data curation, Chaiyut; writing - original draft preparation, Chaiyut; writing - review and editing, Kritsada; visualization, Tosaphol; supervision, Thanatchai.

\section{References}

[1] M. Zielenkiewicz, T. Maksimowicz, and R. Burak-Romanowski, "The protection of DC railway traction power supply systems against direct lightning strike", In: Proc. of 
International Conf. on Lightning Protection, Rzeszow, Poland, pp. 1-6, 2018.

[2] A. Rousseau, G. Rougier, and A. Aragones, "Improved tramway surge protection", In: Proc. of the 34th International Conf. on Lightning Protection, Rzeszow, Poland, pp. 1-7, 2018.

[3] J. Russell, A. Novianto, and U. Kreher, "Systematic design and coordination of earthing, lightning protection electrolysis mitigation for elevated structures supporting DC railway", In: Proc. of Down to Earth Conf., DTEC, Melbourne, Australia, pp. 1-8, 2018.

[4] G. Morita, H. Tanaka, and K. Michishita, "Development of new earthing system inspection method for the evaluation of lightning protection", In: Quarterly Report of RTRI (Railway Technical Research Institute), Vol. 61, No. 1, pp. 40-46, 2020.

[5] L. Zhao, L. Long, S. Yang, and S. Lin, "A Recognition Method for Lightning Disturbance in Traction Power Supply System Based on Wavelet Energy Moment", In: Proc. of Prognostics and System Health Management Conf., Qingdao, China, pp. 1-6, 2019

[6] I. Hendratama, B. Denov, and R. Zoro, "Lightning Protection System Standardization on Indonesian Railway Operation Facilities", In: Proc. of the 2nd International Conf. on High Voltage Engineering and Power Systems (ICHVEPS), Denpasar, Bali, Indonesia. pp. 1-6, 2019

[7] S. Ng, "Designing lightning protection, earthing and bonding system for railways", In: Proc. of the 11th Asia-Pacific International Conf. on Lightning, Hong Kong. pp. 1-4, 2019

[8] V. A. Alrim, S. A. Amanatiadis, A. X. Lalas, and C. S. Antonopoulos, "A circuit human body model for an indirect lightning strike analysed by means of an FDTD method", In: Proc. of the 9th IET International Conference on Computation in Electromagnetics, London, UK, pp. 1-2, 2014.

[9] Z. Bihua, R. Heming, S. Lihua, and G. Cheng, "Calculation of step voltage near lightning current", In: Proc. of Asia-Pacific Radio Science Conference, Qingdao, China, pp. 646-649, 2004.

[10] J. J. Pantoja and F. Roman, "Analysis of a lightning earthing system using electromagnetic simulations", In: Proc. of International Symposium on Lightning Protection, Balneario Camboriu, pp. 104-108, 2015.

[11] A. Gomes, C. Gomes, M. Z. K. A. Kadir, M. Izadi, and M. Rock, "Evaluation of lightning protection systems proposed for small structures by electromagnetic simulation", In: Proc. of the 33rd International Conference on Lightning Protection, Estoril, Portugal, pp. 1-5, 2016.

[12] R. Markowska, A. Sowa, and J. Wiater, "Step and Touch Voltage Distributions at GSM Base Station during Direct Lightning Stroke", In: Proc. of International Conference on High Voltage Engineering and Application, Chongqing, China, pp. 199-202, 2008.

[13] S. Suchanek, V. Hinrichsen, R. Brocke, and K. P. Muller, "Investigations of earth termination systems with respect to optimised step voltages", In: Proc. of International Conference on Lightning Protection, Vienna, Austria, pp.1-7, 2012.

[14] IEC TS 60479-1, "Effects of current on human beings and livestock - Part 1: General aspects", 2005.

[15] M. Nayel, J. Zhao, J. He, Z. Cai, and Q. Wang, "Study of Step and Touch Voltages in Resistive/Capacitive Ground due to Lightning Stroke", In: Proc. of Asia-Pacific Conference on Environmental Electromagnetics, Dalian, China, pp. 56-60, 2006.

[16] J. Gao, I. Munteanu, S. Suchanek, W. F. O. Müller, T. Weiland, and V. Hinrichsen, "Study on the step voltage caused by lightning current with postured voxel-based human body models", In: Proc. of IET 8th International Conference on Computation in Electromagnetics, Wroclaw, Poland, pp.1-2, 2011.

[17] S. Dahal, R. Martin, and S. Paudyal, "Impact of lightning strikes on substation grounding systems", In: Proc. of Australasian Universities Power Engineering Conference, Melbourne, VIC, Australia, pp.1-5, 2017.

[18] C. Tian, Y. Zhang, L. Cai, J. Wang, S. Huang, and Y. Wang, "Lightning transient characteristics of a $500-\mathrm{kV}$ substation grounding grid", In: Proc. of Asia-Pacific International Conference on Lightning, Chengdu, China, pp. 711-715, 2011.

[19] E. Faleiro, F. J. Pazos, G. Asensio, G. Denche, D. García, and J. Moreno, "Interaction Between Interconnected and Isolated Grounding Systems: A Case Study of Transferred Potentials", IEEE Transactions on Power Delivery, Vol. 30, No. 5, pp. 2260 - 2267, 2015.

[20] EN50122-1, "Railway applications-Fixed installations - Electrical safety, earthing and the return circuit - Part 1: Protective provisions against electric shock", 2011.

[21] IEC TS 60479-2, "Effects of current on human beings and livestock - Part 2: Special aspects", 2007.

[22] TIS 24-2548, "Steel bars for reinforced concrete: deformed bars", 2003. 
[23] N. Mrmak, P. van Oorschot, and J. W. Pustjens, "Electrical resistivity", http://www.resistorguide.com/resistivity/, Accesses 20 January 2020

[24] IEC 62305-1, "Protection against lightning Part 1: General principles”, 2010. 